\title{
ESTIMATING INCURRED CLAIMS
}

\section{Benedikt}

Gothenburg

The problem of estimating the final amount after settlement of Motor and General Third Party claims incurred during an underwriting year is of considerable importance for direct writing companies, as well as for reinsurers. While methods of considerable precision have been proposed for direct writing companies' business (ref. I,2), a less exact but simpler method, which is applicable, i.a., to non-proportional reinsurance, could also be of interest.

The method uses the so-called "chain relatives" (ref. 3) computed from the figures for incurred losses similar to those quoted on p. I57, ref. I. The year in which losses $S_{i, j}$ have occurred is designated by the subscript $i$, whilst the years in which the corresponding amount of losses paid plus outstanding has been ascertained (or estimated) are designated by the subscript $j$.

"Chain relatives" are defined as a ratio

$$
a_{i, j}=\frac{S_{i, j=} ;}{S_{i, j}} \quad \begin{aligned}
& i=\mathrm{I}, 2,3, \ldots n ; \\
& j=\mathrm{I}, 2,3, \ldots n-\mathrm{I} ;
\end{aligned}
$$

If the available statistics embrace $n$ years, $a_{i, j}$ can be computed for every $j=\mathrm{I}, 2,3, \ldots n-\mathrm{I}$ but only for $i \leq n-j$. To obtain estimates of $a_{i, j}$ for every $i>n-j$ up to $i=n$ we shall use $E\left(a_{i, j}\right)$ for fixed $j$.

The underlying hypothesis concerning $a_{i, j}$ is that every $a_{i, j}$ consists of a systematic part and of a random part. The random parts can always be assumed to have the mean $=o$. For fixed $j$ the systematic parts are a function of the index for the value of money and of several parameters defining the process of claims settlement. The index for the value of money obviously being constant for each fixed $j$, it is assumed that the other parameters are also constant for fixed $j$. This, of course, presupposes that the average proportion (over the years of occurrence) of settlement of the incurred losses is independent of their initial volume and of the year of occurrence. 
Detailed analysis (the method given on p. 178 , ref. 4 , has been found useful) and numerical applications confirm this hypothesis.

$E\left(a_{i, j}\right)$ for every fixed $j$ can be estimated by taking arithmetic means of the computed $a_{i, j}$ over all $i \leq n-j$. It will be observed that the $a_{i, j}$ tend to I with increasing $j$, thus offsetting somewhat the diminishing precision of the estimates due to the decreasing $i \leq n-j$.

The estimates thus obtained, i.e. the average values of $a_{i, j}$, are multiplied together for each fixed $i$. The resulting coefficients $a_{i}$ are multiplied by the corresponding $S_{i, j}+n+i=1$ to produce the estimates of the final loss amounts after settlement, $S_{i, n}$.

The estimation method outlined above can be illustrated by the following example for $n=5$. This period is used as illustration only, as it is too short for reliable estimation. The loss figures shown in Table I, representing, incidentally, excess losses over and above a low underlying retention, are given in thousands of money units.

\section{Table I}

Years of occurrence

Subsequent years

\begin{tabular}{|c|c|c|c|c|c|c|}
\hline & & I957 & I958 & 1959 & 1960 & I96I \\
\hline I957 $i=$ & I & 432 & 615 & 772 & 397 & 402 \\
\hline $195^{8}$ & 2 & - & 926 & IOII & $85^{8}$ & 1207 \\
\hline I959 & 3 & - & - & $32 \mathrm{I}$ & $4^{80}$ & 293 \\
\hline I960 & 4 & - & - & - & 628 & 109 \\
\hline I96I & 5 & - & - & - & - & 257 \\
\hline
\end{tabular}

To begin with, these figures are rearranged in Table 2, where, for instance, $S_{1,1}=432$ and $S_{3,2}=480$.

\section{Table 2}

\begin{tabular}{ccccccc}
\multicolumn{2}{r}{ Years of occurrence $=i$} & \multicolumn{5}{c}{ Subsequent years $=j$} \\
& & I & 2 & 3 & 4 & 5 \\
1957 & I & 432 & 615 & 772 & 397 & 402 \\
1958 & 2 & 926 & 1011 & 858 & 1207 & \\
1959 & 3 & 321 & 480 & 293 & & \\
1960 & 4 & 628 & 1090 & & & \\
1961 & 5 & 257 & & & &
\end{tabular}

The "chain relatives" can now be computed as shown in Table 3; thus $a_{1,1}=\frac{6 \mathrm{I} 5}{43^{2}}=\mathrm{I} .42$ (rounded off) and, for instance, 
$a_{3,2}=\frac{293}{480}=0.6 \mathrm{I}$. The estimates for $i>n-j$, i.e. the averages for every $j$, are given at the foot of the table. They are also set out (in brackets) for $j \times n-i$; the estimates of $a_{i, 5}$ are here assumed to be $=\mathrm{I}$. Their products appear in column $a_{i}$; these latter, multiplied by $S_{i, n-i+1}$ from Table 2 , produce the required estimates $S_{i, n}$.

\section{Table 3}

$\begin{array}{lcccccccr}i & j= & \mathrm{I} & 2 & 3 & 4 & 5 & a_{t} & S_{i, n} \\ \mathrm{I} & & \mathrm{I} .42 & \mathrm{I} .26 & 0.5 \mathrm{I} & \mathrm{I} . \mathrm{OI} & (\mathrm{I} .00) & (\mathrm{I} . \mathrm{OO}) & 4 \text { O2 } \\ 2 & & \mathrm{I} .09 & 0.85 & \mathrm{I} .4 \mathrm{I} & (\mathrm{I} . \mathrm{OI}) & (\mathrm{I} .00) & (\mathrm{I} .0 \mathrm{I}) & \mathrm{I} 2 \mathrm{I} 9 \\ 3 & & \mathrm{I} .50 & \mathrm{O} .6 \mathrm{I} & (\mathrm{O} .96) & (\mathrm{I} . \mathrm{OI}) & (\mathrm{I} .00) & (\mathrm{O} .97 & 284 \\ 4 & & \mathrm{I} .74 & (\mathrm{O} .9 \mathrm{I}) & (\mathrm{O} .96) & (\mathrm{I} . \mathrm{OI}) & (\mathrm{I} .00) & (\mathrm{O} .88) & 959 \\ 5 & & (\mathrm{I} .44) & (\mathrm{O} .9 \mathrm{I}) & (\mathrm{O} .96) & (\mathrm{I} . \mathrm{OI}) & (\mathrm{I} .00) & (\mathrm{I} .27) & 326\end{array}$

$\begin{array}{lllll}\text { Averages: } & \text { I.44 } & 0.9 \mathrm{I} & 0.96 & \text { I.OI }\end{array}$

Extreme values (for instance, catastrophic losses), possibly present in the statistics, should not be included without some adjustment.

\section{REFERENCES}

[I] N. E. Masterson, "Problems in Motor Insurance - Claim Reserves", ASTIN Bulletin, Vol. II, Part I, Jan. I962.

[2] R. E. BEARD, "Some Actuarial Aspects of Non-Life Insurance Company Management", Het Verz.-Archief, Deel XLII (4), Oct. I965.

[3] H. T. Davis, "Analysis of Economic Time Series" (Bloomington, Ind., I94I).

[4] N. L. Johnson and H. Tetley, "Statistics", Vol. I (Cambridge, I949). 